8-1-2019

\title{
Prioritizing and targeting SBC investments in family planning for married youth in USAID priority countries [2 pages]
}

Breakthrough RESEARCH

Follow this and additional works at: https://knowledgecommons.popcouncil.org/departments_sbsr-rh How does access to this work benefit you? Let us know!

\section{Recommended Citation}

Breakthrough RESEARCH. 2019. "Prioritizing and targeting SBC investments in family planning for married youth in USAID priority countries," Programmatic Research Brief. Washington, DC: Population Council. [2-page brief] 


\section{Prioritizing and targeting SBC investments in family planning for married youth in USAID priority countries}

This document is intended for global and country-level decision-makers, and family planning (FP)/reproductive health (RH) program implementers in USAID FP priority countries. It underscores the need for investments in social behavior change (SBC) interventions in FP programming for married young women. It discusses potential investments based on levels of current use of modern contraception and the potential demand for modern contraception, and is designed to help decision-makers prioritize and target SBC interventions.

\begin{abstract}
Background: Ensuring that young married women have access to modern FP methods is important for supporting them to achieve healthy birth spacing and plan their families. In most countries, contraceptive use among married young women is lower than use among older married women. ${ }^{1}$ However these lower levels of contraceptive use do not always signal unmet need within this group. Decision-makers may underestimate social pressures and other complexities that can lead young married women to desire a pregnancy in order to establish fertility and adhere to a normative role in society. ${ }^{2}$ Decision-makers may also struggle with the right investment decisions for married young women. For instance, how can married young women be best supported to delay first births and achieve healthy timing and spacing of pregnancies? Is low demand limiting the use of modern methods of contraception among married young women and, if so, how can it be increased? And, what combination of service delivery and $\mathrm{SBC}$ interventions is best given the current levels of modern contraceptive use?
\end{abstract}

Evidence has shown that SBC interventions can increase demand for and use of modern contraception. ${ }^{3} \mathrm{SBC}$ recognizes the complexity of targeting married young women and uses tested communication principles and methods to promote healthy decision-making and behavior. Effective SBC interventions are grounded in behavioral theory and recognize that behavior change is more likely to occur in an environment where enabling factors are promoted and barriers are removed. ${ }^{4}$ SBC programs require a multi-component approach and at multiple levels of influence: at the individual level to facilitate youth's empowerment; at the relationship level to promote supportive relationships with partners, parents, and peers; at the community level to change social norms that enable youth to learn about their sexuality, access services, and challenge harmful practices; and at the societal level (policies, laws, and media campaigns) to create structural change that supports adoption of healthy behaviors. $^{5}$

Implications: SBC interventions and messages for increasing contraceptive use to address the needs of married young women should be tailored to each context. The figure below helps decision-makers achieve this aim. Along the bottom of the figure is the share of married young women who have a potential demand for modern contraception. "Potential demand" is defined as the proportion of married young women who do not wish to get

\section{KEY POINTS}

The needs of married youth are unique and must be addressed through tailored programming to address barriers to family planning use.

Tailored investment in social behavior change programming can enhance the effectiveness of other program approaches.

The gap between current demand and potential use of family planning can inform how to prioritize and target programming.

pregnant in the near future. The further to the right a country sits, the larger the share of young women with potential demand for modern contraception. Along the left side of the figure, is the share of married youth using modern contraception, also called the modern contraceptive prevalence rate (mCPR). The orange line cutting through the figure indicates the likely maximum mCPR that could be reached at each current level of potential demand. The vertical gap between a country and this maximum line indicates how much potential there is for further increases in contraceptive use given existing levels of demand. Depending

\section{Breakthrough RESEARCH}

Our project turns evidence into action by providing thought provoking guidance to improve SBC policy and programming, with the goal of improving the costeffectiveness of USAID's health and development strategies. Breakthrough RESEARCH catalyzes SBC by conducting state-of-the-art research and evaluation and promoting evidence-based solutions to improve health and development programs around the world

Breakthrough RESEARCH is made possible by the generous support of the American people through the United States Agency for International Development (USAID) under the terms of cooperative agreement no. AID-OAA-A-17-00018. The contents of this document are the sole responsibility of the Breakthrough RESEARCH and Population Council and do not necessarily reflect the views of USAID or the United States Government.

Population Council

4301 Connecticut Avenue, NW | Suite 280 | Washington, DC 20008 Tel: +1 2022379400 | breakthroughresearch@popcouncil.org breakthroughactionandresearch.org

References available on website. Suggested citation: Breakthrough RESEARCH 2019. "Prioritizing and targeting SBC investments in family planning for married youth in USAID priority countries," Programmatic Research Brief. Washington DC: Population Council. 


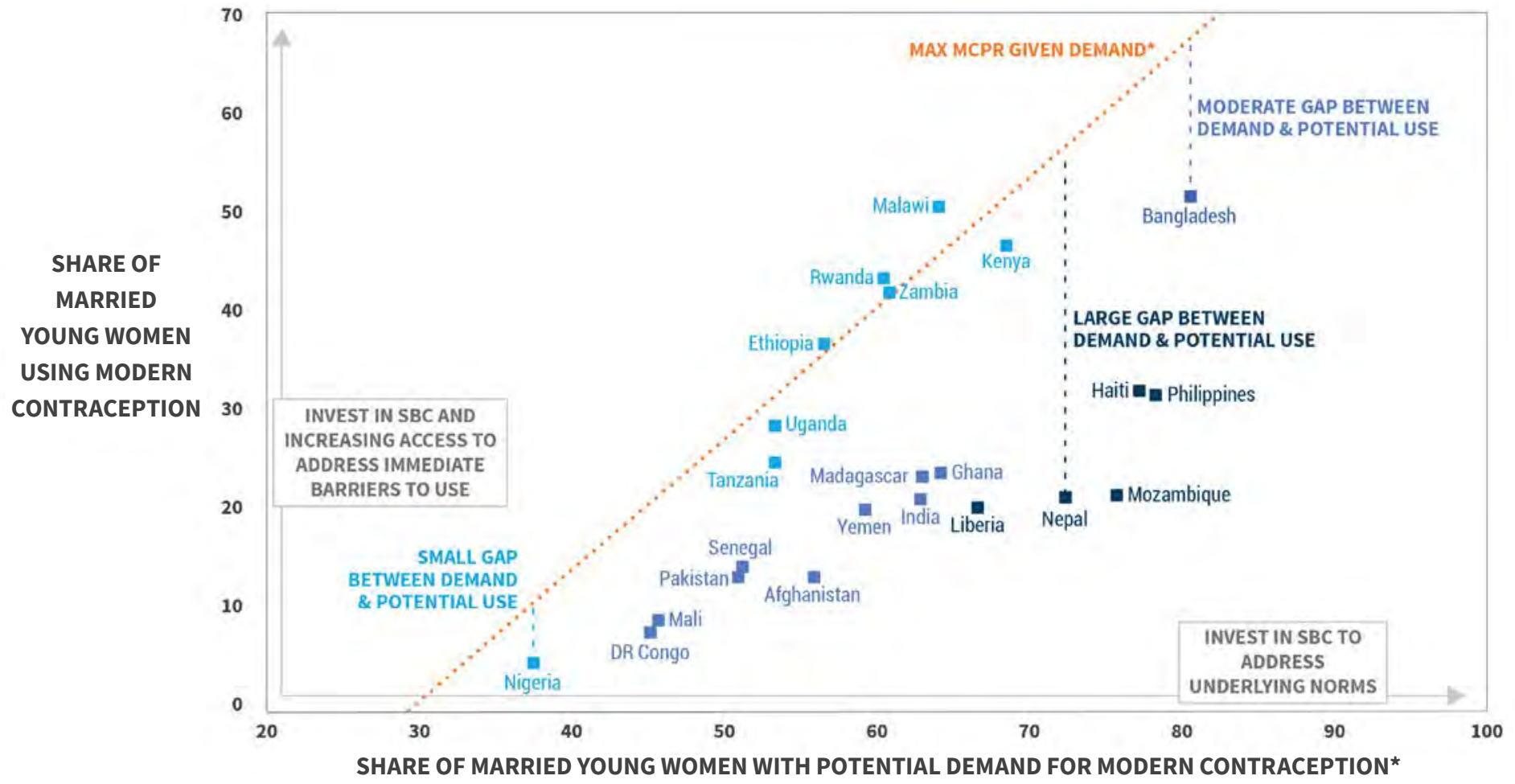

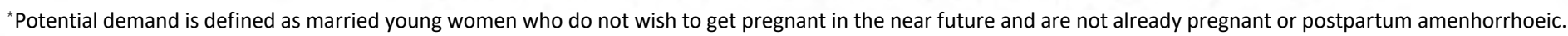

on where a country is positioned, different mixes of SBC interventions and access to contraceptive methods may be needed, and, within SBC approaches, different messages prioritized.

In countries with a small gap between demand and potential use, like Nigeria, efforts to increase use of modern contraception through improved access will be limited because the country already sits at or near the maximum mCPR given existing demand. To see further gains in the use of modern contraception, SBC efforts in these countries will need to increase demand for modern contraception, potentially by addressing norms of early marriage, childbearing, and birth spacing or by improving couple's communication about fertility desires and contraceptive use. Such changes would shift countries to the right (increased demand) and create a larger gap between demand and potential use of modern contraception. Other effective SBC investments may include promoting respectful relationships and teaching husbands to be supportive partners.

In countries with a large gap between demand and potential use, like Nepal, there is existing demand that could be met through improving access, supply, and linkages to FP services. Additionally, addressing young married women's awareness of FP services, self-efficacy to obtain and use modern contraception, and risk perception for unplanned pregnancy through SBC may reduce barriers to modern contraceptive adoption and continuation. Demand generation for under-utilized methods, such as long-acting reversible contraceptives (LARCs) may also be appropriate. Contextual factors in each country must be examined to understand why current use is low relative to demand and to improve program targeting. For example, in Nepal, research has suggested that long periods of spousal separation due to labor migration is responsible for low levels of contraceptive use. ${ }^{6}$
In countries with a moderate gap between demand and potential use, like Bangladesh, decision-makers should consider a mix of programs that target both increasing demand and uptake and continuation of modern contraceptive methods. SBC interventions should focus on increasing awareness of and access to youth-friendly services. Offering informed choice and access to the full suite of modern contraceptive methods is key. Demand generation could potentially focus on other barriers to use, like fear of side effects, risk perception for unplanned pregnancy, self-efficacy to obtain and use modern contraception, or issues related to cost. As more young married women use modern contraception, supply-side issues will become important and resources will need to be dedicated to ensuring an adequate number of providers or task-shifting among providers to offer FP. Further country and sub-national data and analysis may be needed to fully understand the barriers to modern contraceptive use and how to best tailor SBC programs.

Methods: The analysis used in this brief was inspired by the 'maximum contraceptive prevalence demand curve' developed by Track $20{ }^{7}$ This work sought to understand factors that limit the uptake of modern contraceptive use among married young women. We calculated potential demand for all available DHS surveys and graphed its relationship to MCPR among married youth. The orange 'maximum' shown in the graphic comes from fitting a line to the maximum values seen within the data (excluding outliers). Data shown in this brief are from the most recent DHS survey in each country. ${ }^{8}$

Combining these indicators helps contextualize where there is potential for additional increases in contraceptive use among married youth within a country. However, when considering investments within a country, additional data and information is needed to fully understand how best to address the needs of married young women. 